\title{
Sedation Outside the Operating Room: Carried Out to High Levels of Security
}

\author{
Suárez Aguilar Liliana ${ }^{1,2,3,4,5 *}$ \\ ${ }^{1}$ Graduate surgeon MD, Universidad El Bosque, Colombia \\ ${ }^{2}$ Physician specialist in Anesthesiology and Resuscitation, Fundación Santa Fe de Bogotá, Colombia \\ ${ }^{3}$ Specialist in University teaching, Universidad El Bosque, Colombia \\ ${ }^{4}$ Former coordinator of the National Sedation Committee of the Anesthesiology and Resuscitation's Colombian Society (SCARE), Colombia \\ ${ }^{5}$ Scientific director (HYPNOS), Colombia
}

Submission: September 25, 2019; Published: October 18, 2019

*Corresponding author: Suárez Aguilar Liliana, Physician specialist in Anesthesiology and Resuscitation, Fundación Santa Fe de Bogotá, Colombia

Keywords: Sedation Security; Monitoring; Capnography; Outside operating room

Abbreviations: PSA: Procedural Sedation and Analgesia

\section{Mini Review}

The exponential growth of sedation and analgesia procedures (PSA) out of the operating room to relieve anxiety, discomfort and pain, during diagnostic and therapeutic procedures all over the world, has created a lot of controversy in each one of the of the great scientific societies; 2018 was a very important year within the academic output, since some of the most recognized research community as the American, the European and the Canadian, offered management guidelines based on the patient safety's topic. It is essential to be clear, how this anesthetic technique is defined, Canadian guides define it as: "technique of safely administering short-acting sedative or dissociative agents, with or without analgesics, to reduce discomfort, apprehension, and potentially unpleasant memories while minimizing cardiorespiratory depression of patients during diagnostic and therapeutic procedures"[1]. The vast majority of these procedures are not performed in surgery rooms, and it is the responsibility of the anesthesiologist and his team to move the operating room's safety to the place where the procedure is performed; Reason why it is very important to define the scenario and for this I suggest the following classification (Table 1). Intraoperative sedation: Procedures performed within surgery rooms used as a single or combined technique.

a) Sedation outside the operating room: Procedures performed outside the operating room with the standards required by each institution according to the legal regulations of each place. b) In-hospital's sedation outside the operating room: Procedures performed outside the operating room but within a hospital setting. (gastroenterology unit, diagnostic imaging, intensive care unit, emergency room).

c) None-hospital sedation outside the operating room: Procedures performed outside the operating room and outside a hospital setting (medical offices, dental offices, fertility centers, urology centers, aesthetic procedures, etc.)

Table 1: Classification of the procedural sedation and analgesia.

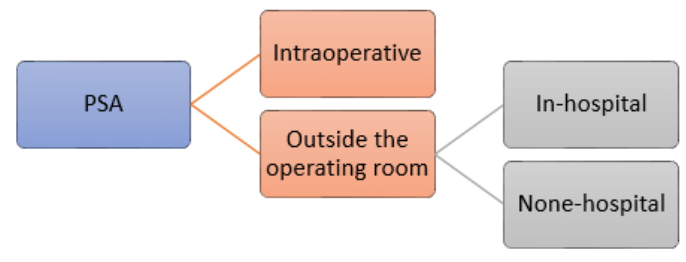

This classification offers a real approach to the type of scenario where each procedure is developed and helps accordingly to the recommendations of the guides, following the specific requirements for the safe realization of the procedural sedation and analgesia. Since 2010 Helsinki declaration, (initiative of several European societies) dictates recommendations regarding the patient's safety in anesthesiology within which there is a specific one, regarding the sedation issue that quotes: "All institutions providing sedation to patients must comply with anesthesiology recognized sedation standards for safe practice" 
[2]. This recommendation highlights the importance of security in each process for the high quality in its performance from all its implementors. The current classification of sedation levels by the American Society of Anesthesiologists (ASA) of: minimal, moderate, deep and general anesthesia [3]; can be the source of a misconception, about a clear limit between each of the states, but sedation is a continuum and in many cases, although, there is a clear objective about the type of sedation that the professional wants to obtain, this may not be achieved, being below or above it, which is where the qualified anesthesiologist can face a series of adverse events that, in inexperienced hands and with inadequate monitoring, could lead to persistent neurological damage or death .This information that is being collected after the creation of the Closed Claims database by the ASA in 1985 to know the lesions caused by anesthesia to improve patient safety [4]; This data brings us closer to real reports of malpractice that leads to definitive damage to patients, where in most cases were preventable.

Security is definitely an issue that goes hand in hand with the specialty, we are recognized as the leaders in this area and that is why it is so important to take sedation out of the operating room to the highest standards in the 3 scenarios of our actions: pre-sedation, sedation and post-sedation. Monitoring is one of the most important aspects at the time of sedation, warn in advance that the patient's clinical condition is deteriorating, allows preventive measures to be taken to improve the patient's clinical condition in the event of an unnoticed change from one level to another of sedation. One of these tools is the use of capnography and this is demonstrated in the recommendations given by the latest guidelines and some systematic reviews. The ASA in its 2018 guide for performing procedures under moderate sedation recommends: "monitoring patient ventilation and oxygenation, including ventilatory function, by observation of qualitative clinical signs, capnography, and pulse oximetry" Based on Metaanalysis of RCTs indicate that the use of continuous end-tidal carbon dioxide monitoring (i.e., capnography) is associated with a reduced frequency of hypoxemic events (i.e., oxygen saturation less than $90 \%$ ) when compared to monitoring without capnography (e.g., practitioners were blinded to capnography results) during procedures with moderate sedation (category A1-B evidence) [5-7]. On the other hand, European guidelines recommend the use of capnography, not only for moderate sedation, but also in all scenarios where sedation is the chosen technique and refers to the following: "facilitating early detection of ventilation problems: should be used in all patients undergoing procedural sedation (very good consensus: level of evidence A: grade of recommendation strong) In addition to continuous monitoring by visual observation, NIBP, ECG and pulse oximetry, capnography should be used for continuous evaluation of ventilation; the addition of capnography to standard monitoring for propofol sedation in adult emergency care reduced, and improved early detection of, hypoxic events" [8-10].
Canadian guides also mention capnography in cases of mandatory use for deep sedation and a useful resource for minimal and moderate sedation stating: "that continuous monitoring of end-tidal carbon dioxide (waveform capnography) is mandatory during general anesthesia and for moderate or deep procedural sedation. For minimal sedation, capnography may be a useful adjunct to detect progression to an unintended deeper level of sedation with associated respiratory depression and is therefore recommended. Capnography is useful in monitoring patient ventilation when it cannot be directly observed (e.g., during magnetic resonance imaging), when multiple sedative agents are utilized, and when the pre-procedural assessment identifies an increased clinical risk for respiratory depression or airway obstruction (e.g., morbid obesity, OSA) [1,11]. It is clear the security approach that is delivered in the latest guides of the different anesthesiology societies in the world, the use of capnography is one of the monitoring tools that shows us the example of this; That is why the importance of raising awareness of the "OUGHT TO BE", sedating is an art, and the anesthesiologist its artist. Every time a sedation procedure is performed outside the operating room, there is a great responsibility regarding meet the minimum safety standards in anesthesia to enforce the principles of bioethics, autonomy, non-maleficence, beneficence and justice in each of the patients that are treated. The invitation is to continue the growth of performing procedures outside the operating room safely and responsibly, to continue developing and training in this field, to continue, at the vanguard as experts in this area.

\section{References}

1. Dobson G, Chong MA, Chow L, Flexman A, Hurdle H et al. (2018) Procedural sedation: a position paper of the Canadian Anesthesiologists' Society. Can J Anaesth 65(12): 1372-1384.

2. Mellin Olsen J, Staender S, Whitaker DK, Smith AF (2010) The Helsinki Declaration on Patient Safety in Anesthesiology. Eur J Anaesthesiol 27(7): 592-597.

3. (2007) Continuum of depth of sedation: definition of general anesthesia and levels of sedation/analgesia. American Society of Anesthesiologists.

4. Metzner J, Posner KL, Lam MS, Domino KB (2011) Closed claims' analysis. Best Pract Res Clin Anaesthesiol 25(2): 263-276

5. (2018) Practice Guidelines for Moderate Procedural Sedation and Analgesia 2018. Anesthesiology 128: 437-479.

6. Beitz A, Riphaus A, Meining A, Kronshage T, Geist C et al. (2012) Capnographic monitoring reduces the incidence of arterial oxygen desaturation and hypoxemia during propofol sedation for colonoscopy: A randomized, controlled study (ColoCap Study). Am J Gastroenterol 107(8): 1205-1212.

7. Mehta PP, Kochhar G, Albeldawi M, Kirsh B, Rizk M et al. (2016) Capnographic monitoring in routine EGD and colonoscopy with moderate sedation: A prospective, randomized, controlled trial. Am J Gastroenterol 111(3): 395-404.

8. Hinkelbein J, Lamperti M, Akeson J, Santos J, Costa J et al. (2018) European Board of Anesthesiology guidelines for procedural sedation and analgesia in adults. Eur J Anaesthesiol 35(1): 6-24. 
9. Arakawa H, Kaise M, Sumiyama K, Saito S, Suzuki T et al. (2013) Does pulse oximetry accurately monitor a patient's ventilation during sedated endoscopy under oxygen supplementation? Singapore Med J 54(4): 212-215.

10. Deitch K, Miner J, Chudnofsky CR, Dominici P, Latta D et al. (2010) Does end tidal $\mathrm{CO} 2$ monitoring during emergency department procedural

This work is licensed under Creative Commons Attribution 4.0 License

DOI: 10.19080/JAICM.2019.09.555769 sedation and analgesia with propofol decrease the incidence of hypoxic events? A randomized, controlled trial. Ann Emerg Med 55(3): 258264

11. Saunders R, Struys MM, Pollock RF, Mestek M, Lightdale JR (2017) Patient safety during procedural sedation using capnography monitoring: a systematic review and meta-analysis. BMJ Open 7(6): e013402.

\section{Your next submission with Juniper Publishers} will reach you the below assets

- Quality Editorial service

- Swift Peer Review

- Reprints availability

- E-prints Service

- Manuscript Podcast for convenient understanding

- Global attainment for your research

- Manuscript accessibility in different formats

( Pdf, E-pub, Full Text, Audio)

- Unceasing customer service

Track the below URL for one-step submission https://juniperpublishers.com/online-submission.php 